\title{
BIRTH OUTCOMES OF CHILDREN BORN TO WOMEN WITH RHEUMATOID ARTHRITIS
}

\author{
Éva Pósfai', Ferenc Bánhidy², Róbert Urbán ${ }^{3}$, Andrew E. Czeizel ${ }^{1}$ \\ ${ }^{1}$ Foundation for the Community Control of Hereditary Diseases, Budapest, Hungary \\ ${ }^{2}$ Second Department of Obstetrics and Gynaecology, School of Medicine, Semmelweis University, Budapest, Hungary \\ ${ }^{3}$ Department of Personality and Health Psychology, Eötvös Loránd University, Budapest, Hungary
}

\section{SUMMARY}

Aim: The aim of the study was to estimate the possible risk of adverse birth outcomes of children born to mothers with rheumatoid arthritis (RA).

Methods: The dataset of large population-based Hungarian Case-Control Surveillance System of Congenital Abnormalities from 1980-1996 was evaluated including 22,843 cases with congenital abnormalities and 38,151 matched controls without any defect.

Results: 36 cases $(0.16 \%)$ had mothers with RA, while 68 controls $(0.18 \%)$ were born to mothers without $\mathrm{RA}(\mathrm{OR}=0.9,95 \% \mathrm{Cl}=0.3-1.6)$. A higher risk for congenital abnormalities in the offspring of pregnant women with RA was not found. In fact there was a larger mean birth weight in the newborns without any defect of mothers with RA and it was associated with a somewhat lower rate of low birth weight.

Conclusion: RA seems to have a beneficial effect not only for pregnant women but for their foetuses as well.

Key words: rheumatoid arthritis, pregnancy, congenital abnormalities, birth weight, preterm birth, population-based case-control study

Address for correspondence: E. Pósfai, Foundation for the Community Control of Hereditary Diseases, 1026 Törökvész lejtő 32, Budapest, Hungary. E-mail: evaposfay@gmail.com

\section{INTRODUCTION}

Rheumatoid arthritis (RA) is a chronic inflammatory/autoimmune disease characterized by symmetrical polyarthritis of the small joints of the hands and feet $(1,2)$. RA affects $0.5-1.0 \%$ of adults with 5-50 per 100,000 new cases annually (1). Women suffer from the disease two to four times more frequently than men, many cases could appear at the age of 20 to 40 years, which is the period of the highest child-bearing potential. Thus the prevalence of RA is estimated 1 in 1,000-2,000 pregnant women (2). Since 1938, the ameliorating effect of pregnancy on RA has been well known, because the improvement of symptoms usually occurs in the first trimester and increases as pregnancy progresses in $75 \%$ of RA pregnancies (3). The suppressed immune relationship between the mother and the foetus might be responsible for the favourable pattern of RA in pregnant women (4). Authors suppose that hormonal factors such as progesterone depress the immune response due to modulating Th1/Th2 cytokine balance (5-7). Other reports support not just the role of progesterone but the disease-modulating role of estrogen and cortisol as well. However, other authors have not reported any significant evidence (8). On the other hand, most RAs exacerbate during the postpartum period or less often RA starts during puerperium within four to six months after delivery $(3,9-13)$. In addition, clinical picture of RA may show remission in a minor part of pregnant women (14-18). The complex hormonal and immunological alterations of pregnancy may have an effect on immunoregulation of RA. Some investigations suggested that the effect of diminished IFNgamma production and misbalance in IL- 6 and IL-12 production also could be responsible for the RA remission in pregnancy. The maternal immune response to foetal paternally-inherited class II HLA antigens, CD8+ and CD4+ T cells, placental gamma globulins, and changes in serum foetal DNA levels (trophoblast derived) may also play an important role in the pregnancy-induced remission of RA (11, 14, 19-22).

The effect of RA in pregnant woman on foetuses is less known, we did not find any data regarding higher risk for structural birth defects, i.e. congenital abnormalities (CAs) in the international literature (23). Bowden et al. (24) reported that infants born to mothers with arthritis and inflammatory polyarthritis had lower mean birth weight than control subjects $(3.3+0.5$ vs. $3.5+0.4$ $\mathrm{kg} ; \mathrm{p}=0.004)$. Thus, the aim of this study was to evaluate birth outcomes of newborn infants born to mothers affected by RA in the population-based Hungarian Case-Control Surveillance of Congenital Abnormalities (HCCSCA) (25).

\section{MATERIALS AND METHODS}

The evaluation of HCCSCA is based on the comparison of RA prevalence during pregnancy in the mothers of cases with different CAs and in the mothers of matched controls without any $\mathrm{CA}$.

\section{Subjects}

Cases affected with CA were selected from the dataset of the Hungarian Congenital Abnormality Registry (HCAR), from 1980-1996 for the HCCSCA (26) Diagnosis of CA was based on the compulsory notification of physicians from birth until the end of the first postnatal year to HCAR, and on autopsy reports because autopsy is mandatory for all infant deaths. Since 1984, foetal defects diagnosed in prenatal diagnostic centres with or without termination of pregnancy have also been included into HCAR. 
CAs were differentiated into two groups: major CAs (without medical intervention CAs cause handicap or death) and mild (CAs require medical intervention but life expectancy is good). In addition, two main categories of cases with CAs were differentiated: isolated (only one organ affected) and multiple (concurrence of two or more CAs in the same person affecting at least two different organ systems).

The recorded total (birth and foetal) prevalence of cases with CA diagnosed from the second trimester of pregnancy through the age of one year was 35.0 per 1,000 informative offspring (liveborn infants, stillborn foetuses and electively terminated malformed foetuses) in HCAR from 1980-1996, though the expected rate was 65.3 per 1,000 (27). However, about $90 \%$ of major CAs were recorded in HCAR during the 17 years of the study period (25). The proportion of liveborn infants, stillborn foetuses and electively terminated malformed foetuses was $97.1 \%, 1.1 \%$ and $1.8 \%$, respectively.

Controls were defined as newborn infants without CA and they were selected from the National Birth Registry of the Central Statistical Office for HCCSCA. In general, two controls were matched to every case according to sex, birth week in the year, and district of parents' residence.

Gestational time was calculated from the first day of the last menstrual period. Beyond medically recorded birth weight (g) and gestational age at delivery (wk) on the discharge summaries (in Hungary practically all deliveries occur in inpatient obstetric clinics), the rate of low birth weight $(<2,500 \mathrm{~g})$ and the rate of preterm births $(<37$ weeks) were analyzed in the newborns of pregnant women examined. The critical period of most major CAs is the second and/or third gestational month (28).

\section{Collection of Prevalence Data and Confounding Factors}

\section{Prospective Medically Recorded Data}

The mothers of cases and controls were asked in an explanatory letter to send us the prenatal maternity logbook and other medical records particularly discharge summaries concerning their diseases during the pregnancy and their child's CA. Prenatal care is mandatory for pregnant women in Hungary (if mother does not visit prenatal care clinic, she does not receive a maternity grant and leave), thus nearly $100 \%$ of pregnant women visited prenatal care clinics, on average 7 times during pregnancy. The first visit was between the 6th and 12th gestation week. The task of obstetricians was to record all pregnancy complications, maternal diseases and related drug treatments in the prenatal maternity logbook.

\section{Retrospective Self-reported Maternal Information}

A structured questionnaire with a list of medicinal products and diseases, plus a printed informed consent form was also mailed to the mothers immediately after the selection of cases and controls. To standardize the answers, mothers were asked to read the enclosed lists of medicinal products and diseases as a memory aid before they filled in the questionnaire. Mothers were also asked to sign an informed consent. Unfortunately, retrospective maternal information regarding smoking habit during pregnancy was unreliable (29).
The mean + SD time elapsed between the birth or pregnancy termination and the return of the "information package" (questionnaire, logbook, discharge summary, and informed consent form) in our prepaid envelope was $3.5+1.2$ and $5.2+2.9$ months in the case and control groups, respectively.

\section{Supplementary Data Collection}

Regional nurses were asked to visit all non-respondent case mothers and they helped mothers to fill in the same questionnaire, evaluated the available medical records, in addition, obtained data regarding smoking (cigarette/day) and drinking habits through a cross interview of mothers and fathers or other close relatives living together and the so-called family consensus was recorded. Regional nurses visited only 200 non-respondent (30) and 600 respondent (31) control mothers in two validation studies because the Ethics Committee considered this follow-up to be disturbing to the parents of all healthy children. Regional nurses used the same method in these control mothers as in non-respondent case mothers.

Overall, the necessary information was available on $96.3 \%$ of cases $(84.4 \%$ from reply to the mailing, $11.9 \%$ from the nurse visit) and $83.0 \%$ of the controls ( $81.3 \%$ from reply, $1.7 \%$ from visit). Informed consent form was signed by $98 \%$ of mothers, names and addresses were deleted in the rest of $2 \%$. The procedure of data collection in HCCSCA was changed in 1997, however, recent data have not been validated at the time of this analysis, thus only the data set of 17 years between 1980 and 1996 is evaluated here.

\section{Variables Evaluated in the Study}

The Hungarian medical doctors followed the internationally accepted diagnostic criteria of RA in the study. The diagnosis of pregnancy complications and other chronic maternal diseases were based on medical records of the prenatal maternity logbook. Acute diseases, drug treatments and pregnancy supplements were evaluated on the basis of both medical records in the prenatal maternity logbook and maternal information in the questionnaire. Among potential confounding factors, maternal age and birth order (based on the discharge summary of delivery), marital and employment status (based on the questionnaire) were evaluated. The employment status was the indicator of socio-economic status (25).

\section{Statistical Analysis}

SAS version 8.02 (SAS Institute Ins., Cary, North Carolina, USA) was used for statistical analyses of data. First, the main maternal variables were evaluated in case and control pregnant women using Student $t$ test for quantitative and chi-square test for categorical variables at the comparison of pregnant women with RA and without RA as reference. The incidence/prevalence of other maternal diseases, drug intakes and supplements particularly folic acid and folic acid containing multivitamins during pregnancy as well as pregnancy complications were compared between the groups of case and control mothers with RA using odds ratios (OR) with $95 \%$ confidence intervals (CI). The aim of the study was the comparison of birth outcomes of newborn infants born to women affected by RA, thus Student $t$ test was used for quantitative gestational age at delivery and birth weight 
Table 1. Characteristics of case and control mothers with rheumatoid arthritis (RA) and without RA as reference

\begin{tabular}{|c|c|c|c|c|c|c|c|c|}
\hline \multirow{3}{*}{$\begin{array}{l}\text { Variables } \\
\text { Quantitative }\end{array}$} & \multicolumn{4}{|c|}{ Case mothers } & \multicolumn{4}{|c|}{ Control mothers } \\
\hline & \multicolumn{2}{|c|}{$\begin{array}{l}\text { with RA } \\
(\mathrm{N}=36)\end{array}$} & \multicolumn{2}{|c|}{$\begin{array}{l}\text { without RA } \\
(\mathrm{N}=22,807)\end{array}$} & \multicolumn{2}{|c|}{$\begin{array}{l}\text { with RA } \\
(\mathrm{N}=68)\end{array}$} & \multicolumn{2}{|c|}{$\begin{array}{l}\text { without RA } \\
(\mathrm{N}=38,083)\end{array}$} \\
\hline & $\mathrm{n}$ & $\%$ & $n$ & $\%$ & $\mathrm{n}$ & $\%$ & $n$ & $\%$ \\
\hline \multicolumn{9}{|l|}{ Maternal age, yr. } \\
\hline$<19$ & 1 & 2.8 & 2,506 & 11.0 & 1 & 1.5 & 3,276 & 8.6 \\
\hline $20-29$ & 20 & 55.6 & 15,573 & 68.3 & 46 & 67.6 & 27,556 & 72.4 \\
\hline 30 or more & 15 & 41.7 & 4,729 & 20.7 & 21 & 30.9 & 7,251 & 19.0 \\
\hline Mean SD & 29.0 & 6.3 & 25.2 & 5.3 & 26.9 & 5.6 & 25.5 & 5.3 \\
\hline \multicolumn{9}{|l|}{ Birth order } \\
\hline 1 & 13 & 36.1 & 10,695 & 46.9 & 25 & 36.8 & 18,184 & 47.7 \\
\hline 2 or more & 23 & 63.9 & 12,112 & 53.1 & 43 & 63.2 & 19,899 & 52.3 \\
\hline Mean SD & 2.3 & 1.2 & 1.9 & 1.1 & 1.9 & 0.9 & 1.7 & 0.9 \\
\hline Categorical & $\mathrm{n}$ & $\%$ & $\mathrm{n}$ & $\%$ & $\mathrm{n}$. & $\%$ & $\mathrm{n}$ & $\%$ \\
\hline Unmarried & 2 & 5.6 & 1,267 & 5.6 & 2 & 2.9 & 1,470 & 3.9 \\
\hline \multicolumn{9}{|l|}{ Employment status } \\
\hline Professional & 6 & 16.7 & 1,971 & 8.6 & 7 & 10.3 & 4,416 & 11.6 \\
\hline Managerial & 7 & 19.4 & 5,090 & 22.3 & 18 & 26.5 & 10,247 & 26.9 \\
\hline Skilled worker & 9 & 25.0 & 6,492 & 28.5 & 24 & 35.3 & 11,884 & 31.2 \\
\hline Semiskilled worker & 8 & 22.2 & 4,189 & 18.4 & 12 & 17.6 & 6,149 & 16.1 \\
\hline Unskilled worker & 3 & 8.3 & 1,773 & 7.8 & 2 & 2.9 & 2,185 & 5.7 \\
\hline Housewife & 2 & 5.6 & 2,404 & 10.5 & 1 & 1.5 & 2,353 & 6.2 \\
\hline Others & 1 & 2.8 & 888 & 3.9 & 4 & 5.9 & 849 & 2.2 \\
\hline
\end{tabular}

while OR with $95 \%$ CI for categorical variables as the rate of preterm birth and low birth weight. Then the occurrence of RA during the pregnancy in specific CA groups of cases and in their matched controls were compared, and adjusted OR with $95 \%$ CI were evaluated in conditional logistic regression model. Confounding variables were analyzed by comparing OR for RA in the model with and without inclusion of the potential confounding variables. Finally, maternal age $(<20 \mathrm{yr}, 20-29 \mathrm{yr}$, and $30 \mathrm{yr}$ or more), parity/birth order (first delivery or one or more previous deliveries) and employment status were included into the model as potential confounders.

\section{RESULTS}

The case group consisted of 22,843 malformed newborns or foetuses (informative offspring), of whom 89 (0.4\%) had mothers with reported or medically recorded RA. The total number of births in Hungary was 2,146,574 during the study period between 1980 and 1996, thus 38,151 controls represented $1.8 \%$ of all births. Of 38,151 controls, $164(0.4 \%)$ were born to mothers with reported or medically recorded RA. However, our validation studies based on the home visit and personal check-up of available medical documents showed that the reliability of RA diagnosis based only on maternal information was questionable (arthrosis, pains, rheumatism, or synovitis were reported as RA). Therefore, RA was finally evaluated only in 36 case mothers $(0.16 \%)$ and $68(0.18 \%)$ control mothers with medical recorded
RA in the prenatal maternity logbook. Obviously obstetricians in the prenatal care clinics copied this diagnosis from the available medical documents of pregnant women. There was no difference in the prevalence of RA between case and control mothers (OR with $95 \% \mathrm{CI}=0.9,0.3-1.6$ ). The onset of RA was prior to conception in all pregnant women.

The main variables of mothers with and without RA, as reference, are shown in Table 1. The mean maternal age was higher in pregnant women with RA particularly in case mothers due to the larger proportion of females over 30 years. The mean birth order was also higher in pregnant women with RA compared to pregnant women without RA. However, the mean birth order was also higher both in case mother with or without RA than in control mothers with or without RA. There was no significant difference in the rate of unmarried women among the study groups. The distribution of employment status showed significant difference between case and control mothers with RA. The proportion of low socio-economic status including semi- and unskilled workers and housewives was $36.1 \%$ in case mothers with RA and this rate exceeded the rate of control mothers with RA (22.0\%). However, there was no significant difference between pregnant women with or without RA in the case and control groups. Housewives belonged to the lower socio-economic class in Hungary.

Among pregnancy complications, only pregnancy related iron deficient anaemia was higher in both case mothers (33.3\%) and control mothers $(30.9 \%)$ with RA than in case $(14.2 \%)$ and control (16.6\%) mothers without RA, respectively. Gestational hypertension did not occur in pregnant women with RA while 
Table 2. Incidence of acute maternal disease groups and prevalence of chronic maternal diseases during the pregnancy in case and control mothers with $R A$ and without $R A$ as reference

\begin{tabular}{|c|c|c|c|c|c|c|c|c|c|c|}
\hline \multirow[t]{2}{*}{ Acute disease groups } & \multicolumn{2}{|c|}{$\begin{array}{l}\text { Case mothers } \\
\text { without } R A \\
(\mathrm{~N}=22,807)\end{array}$} & \multicolumn{2}{|c|}{$\begin{array}{c}\text { Case mothers with } \\
\text { RA } \\
(\mathrm{N}=36)\end{array}$} & \multicolumn{2}{|c|}{$\begin{array}{c}\text { Control mothers } \\
\text { with without } R A \\
(N=38,083)\end{array}$} & \multicolumn{2}{|c|}{$\begin{array}{l}\text { Controls mothers } \\
\text { with RA } \\
(N=68)\end{array}$} & \multicolumn{2}{|c|}{ Comparison } \\
\hline & $\mathrm{n}$ & $\%$ & $\mathrm{n}$ & $\%$ & $\mathrm{n}$ & $\%$ & $\mathrm{n}$ & $\%$ & OR & $95 \% \mathrm{Cl}$ \\
\hline Influenza-common cold* & 4,922 & 21.6 & 14 & 38.9 & 7,032 & 18.5 & 17 & 25.0 & 1.91 & $0.80-4.54$ \\
\hline Respiratory system & 2,116 & 9.3 & 7 & 19.4 & 3,459 & 9.1 & 5 & 7.4 & 3.04 & $0.89-10.40$ \\
\hline Digestive system & 630 & 2.8 & 3 & 8.3 & 793 & 2.1 & 3 & 4.4 & 1.97 & $0.38-10.30$ \\
\hline Urinary tract & 1,586 & 7.0 & 4 & 11.1 & 2,296 & 6.0 & 3 & 4.4 & 2.71 & $0.57-12.83$ \\
\hline Genital organs & 1,622 & 7.1 & 4 & 11.1 & 2,851 & 7.5 & 5 & 7.4 & 1.58 & $0.40-6.27$ \\
\hline Others & 374 & 1.6 & 0 & 0.0 & 425 & 1.1 & 1 & 1.5 & $\mathrm{~N} / \mathrm{A}$ & $\mathrm{N} / \mathrm{A}$ \\
\hline \multicolumn{11}{|l|}{ Chronic diseases } \\
\hline Diabetes mellitus & 155 & 0.7 & 1 & 2.8 & 225 & 0.6 & 4 & 5.9 & 0.46 & $0.05-4.25$ \\
\hline Epilepsy & 93 & 0.4 & 0 & 0.0 & 88 & 0.2 & 0 & 0.0 & $\mathrm{~N} / \mathrm{A}$ & $\mathrm{N} / \mathrm{A}$ \\
\hline Migraine & 1,106 & 4.8 & 3 & 8.3 & 1,983 & 5.2 & 7 & 10.3 & 0.79 & $0.19-3.27$ \\
\hline Thyroid diseases & 84 & 0.4 & 1 & 2.8 & 146 & 0.4 & 1 & 1.5 & 1.91 & $0.12-31.54$ \\
\hline Hypertension (essential) & 1,604 & 7.0 & 4 & 11.1 & 2,664 & 7.0 & 3 & 4.4 & 2.71 & $0.57-12.83$ \\
\hline Heart diseases & 136 & 0.6 & $1^{* *}$ & 2.8 & 168 & 0.4 & $1^{* *}$ & 1.5 & 1.70 & $0.28-1.73$ \\
\hline Varicose veins & 331 & 1.5 & 1 & 2.8 & 560 & 1.5 & 0 & 0.0 & $\mathrm{~N} / \mathrm{A}$ & $\mathrm{N} / \mathrm{A}$ \\
\hline Phlebitis/thrombophlebitis & 339 & 1.5 & 3 & 8.3 & 567 & 2.5 & 8 & 11.8 & 0.77 & $0.44-1.23$ \\
\hline Hemorrhoids & 789 & 3.5 & 6 & 16.7 & 1,604 & 4.2 & 13 & 19.1 & 0.94 & 0.224 .00 \\
\hline
\end{tabular}

*with secondary complications

** supraventricular paroxysmal tachycardia

gestational diabetes was diagnosed only in one case mother. The rate of preeclampsia was not significantly higher in case mothers (5.6\%) and control mothers (4.4\%) with RA than in case mothers $(2.9 \%)$ and control mothers $(3.0 \%)$ without RA.

The higher incidence of acute maternal diseases was recorded in pregnant women with RA than in pregnant women without RA, particularly in case mothers (Table 2). However, the rates of these diseases were not significantly higher in case mothers with RA and in controls mothers with RA.

The prevalence of chronic diseases is also shown in Table 2. The rate of migraine, chronic/essential hypertension, phlebitis/ thrombophlebitis and hemorrhoids was higher in both case mothers and control mothers with RA than in case and control mothers without RA. However, their rate did not show significant difference between case and control mothers with RA due to the limited number of pregnant women with RA.

Obvious difference was seen in the frequency of drugs used for the treatment of RA in pregnant women with and without RA. Of 36 case mothers with RA, 16 (44.4\%) were treated with NSAID (diclofen 12 and naproxen 4) while 6(16.6\%) women with indometacin. Of 68 control mothers with RA, only 18 (26.5\%) received NSAID (diclofen 8 and naproxen 10) and 2 indometacin treatment. The frequency of NSAID and indometacin treatments was $0.1 \%$ in the combined groups of pregnant women without RA. The most frequently used drugs were dipyrone in both case mothers (24, $66.7 \%)$ and control mothers $(18,26.5 \%)$ with RA while the proportion of this drug was about $6 \%$ in the combined reference group.

Pregnancy supplements were evaluated separately because folic acid and folic acid containing multivitamins have a protective effect for neural-tube defects and some other CAs, in addi- tion, they are sensitive indicators of the level of preconception care. Case mothers (58.3\%) and control mothers (66.2\%) with RA used more frequently folic acid than case mothers (49.2\%) and control mothers (54.4\%) without RA. Only one type of $3 \mathrm{mg}$ folic acid tablet was available in Hungary during the study period. In general, daily 1-3 tablets of folic acid were used. Folic acid containing micronutrient combinations, the so-called multivitamins were used rarely. The use of iron products was also more frequent in pregnant women with RA than in pregnant women without RA. However, the higher use of cholecalciferol (Vitamin D) in case mothers (44.4\%) and control mothers (30.9\%) with RA compared to case mothers $(26.7 \%)$ and control mothers $(26.6 \%)$ without RA is also noteworthy.

Birth outcomes are worth evaluating only in controls (Table 3) because CAs may have a more robust effect for these variables than RA, furthermore, the number of newborns is too low in the group of cases. There was no difference in the sex ratio and twins $(2: 2.9 \%$ vs. $408: 1.1 \%)$ in the newborns of pregnant women with or without RA. The somewhat longer gestational age at delivery $(0.1 \mathrm{wk})$ was associated with some decrease in the rate of preterm birth in newborns of mothers with RA compared to the reference group which reflected the Hungarian population data. The mean birth weight was significantly higher ( $139 \mathrm{~g})$ in newborn infants born to mothers with RA and it was associated with a lower rate of low birth weight.

Finally, we analyzed the prevalence of RA in the mothers of cases with specified CAs and in the mothers of their matched controls without any CA (Table 4). The total rate of CA in cases was not higher, the OR was 0.9 , i.e. less than 1.0. Only specified CA groups including at least 2 cases were evaluated separately. Of 
Table 3. Birth outcomes in newborn infants (controls without $C A$ ) born to mothers with RA and mothers without RA as reference

\begin{tabular}{|l|c|c|c|c|c|c|}
\hline \multirow{2}{*}{ Variables } & \multicolumn{2}{|c|}{$\begin{array}{c}\text { Controls of RA mothers } \\
(\mathrm{N}=68)\end{array}$} & \multicolumn{4}{|c|}{$\begin{array}{c}\text { Controls of no-RA mothers } \\
(\mathrm{N}=38,083)\end{array}$} \\
\hline & Mean & SD & Mean & SD & $\mathrm{t}$ & $\mathrm{p}$ \\
\hline Gestational age $(\mathrm{wk})^{*}$ & 39.5 & 1.8 & 39.4 & 2.1 & 0.4 & 0.695 \\
\hline Birth weight $(\mathrm{g})^{*}$ & 3,409 & 504 & 3,275 & 511 & 2.2 & 0.031 \\
\hline Categorical & $\mathrm{n}$ & $\%$ & $\mathrm{n}$ & $\%$ & $\mathrm{OR}$ & $95 \% \mathrm{Cl}$ \\
\hline Preterm birth* & 5 & 7.3 & 3,493 & 9.2 & 0.78 & $0.48-2.94$ \\
\hline Low birth weight** $^{*}$ & 2 & 2.9 & 2,163 & 5.7 & 1.50 & $1.02-3.96$ \\
\hline
\end{tabular}

*adjusted for maternal age, birth order and employment status

**adjusted for maternal age, birth order, employment status and gestational age

Bold number show significant association

Table 4. Matched analysis to estimate the association between maternal RA during pregnancy and different congenital abnormalities (CAs) in their offspring

\begin{tabular}{|c|c|c|c|c|c|}
\hline \multirow{2}{*}{ Study groups } & \multirow{2}{*}{ Total $n$} & \multicolumn{2}{|c|}{ Study pregnancy } & \multicolumn{2}{|c|}{ Adjusted* } \\
\hline & & $\mathrm{n}$ & $\%$ & OR & $95 \% \mathrm{Cl}$ \\
\hline Controls & 38,151 & 68 & $0.2(0.18)$ & \multicolumn{2}{|c|}{ Reference } \\
\hline \multicolumn{6}{|l|}{ Isolated CA } \\
\hline Cleft lip + cleft palate & 1,375 & 3 & 0.2 & 1.2 & $0.4-3.9$ \\
\hline Obstructive urinary CA & 343 & 2 & 0.6 & 3.3 & $0.8-13.5$ \\
\hline Hypospadias & 3,038 & 5 & 0.2 & 0.9 & $0.4-2.3$ \\
\hline Cardiovascular CA & 4,480 & 8 & 0.2 & 1.0 & $0.5-2.1$ \\
\hline Undescended testis & 2,052 & 3 & 0.1 & 0.8 & $0.3-2.6$ \\
\hline Clubfoot & 2,425 & 5 & 0.2 & 1.2 & $0.5-2.9$ \\
\hline Poly/syndactyly & 1,744 & 3 & 0.2 & 1.0 & $0.3-3.1$ \\
\hline Other isolated CAs & 6,037 & $5^{* *}$ & 0.1 & 0.9 & $0.5-3.3$ \\
\hline Multiple CAs & 1,349 & 2 & 0.1 & 0.8 & $0.2-3.4$ \\
\hline Total & 22,843 & 36 & $0.2(0.16)$ & 0.9 & $0.6-1.3$ \\
\hline
\end{tabular}

*adjusted for maternal age, birth order and employment status

${ }^{* *}$ neural-tube defect (spina bifida), posterior cleft palate, congenital hydrocephaly, congenital limb deficiency

these 36 CAs, 8 were affected with cardiovascular CA (ventricular septal defect 3 , atrial septal defect, type II 2, transposition of great arteries, common atrioventricular canal, i.e. endocardial cushion defect, patent ductus arteriosus 1-1), the most common CAs. In addition, 5-5 cases had hypospadias and clubfoot, while cleft lip + palate, undescended testis and polysyndactyly occurred in 3-3 cases, respectively. The component CAs of 2 multimalformed cases were the following: hypospasias + undescended testis + congenital inguinal hernia (the so-called GAM complex) and cleft lip + undescended testis.

\section{DISCUSSION}

Studies have demonstrated that women's concerns regarding the foetal safety and the adverse effects that RA disease might have on the health and care-giving capacities of the mother led to a significant decrease in the number of pregnancies $(1,2,32,33)$. Thus it is necessary to reveal evidence-based risk and benefits of RA in pregnant women.

Our study confirmed that RA occurs in women with advanced age and with lower socio-economic status. The higher incidence of acute infectious diseases in pregnant women with RA may be connected with the autoimmune origin of RA. In addition, the higher risk of vascular diseases such as migraine, chronic/ essential hypertension, phlebitis and hemorrhoids in pregnant women with RA is worth mentioning because patients with RA may have also extra-articular manifestations, e.g. diseases of blood vessels. Chronic hypertension may be associated with the higher risk of cardiovascular CAs and esophageal atreia/stenosis (34). However, there was no higher risk for gestational hypertension and pre-eclampsia in pregnant women with RA in the study. Finally, the higher rate of iron deficient anaemia during the pregnancy of women with RA is noteworthy and it explains the higher use of irons. This association may be partly connected with the higher prevalence of hemorrhoids.

The data set of the population-based HCCSCA did not show higher risk for the total rate of CAs and for any type of specified CAs in the offspring of pregnant women with RA.

The pattern of birth outcomes was unexpected. There was somewhat but not significantly longer gestational age at delivery, however, mean birth weight of controls without CA born to mothers affected with RA was significantly higher. It can be associated with a lower rate of low birth weight in infants born to women 
with RA having lower socio-economic status. Thus RA seems to have a beneficial effect not only for pregnant women but for the foetuses as well. The Arthritis Research Campaign Epidemiology Unit from the University of Manchester, UK, reported lower mean birth weight of newborn infants born to mothers with arthritis and inflammatory polyarthritis (24). This difference may be connected with the different maternal diagnosis or selection bias. In general, institutions with high medical standard for the specified diseases have the most severe patients while HCCSCA includes unselected population-based data set.

A better medical care (e.g. higher use of folic acid) and drug treatments $(33,35-37)$ of pregnant women with RA may also have an impact on more beneficial birth outcomes.

The aim of the study was to evaluate the birth outcomes of pregnant women affected by RA and our study did not indicate that maternal RA and related drug treatments were associated with a higher risk of CA. In fact the newborns had higher mean birth weight. Thus the well-known beneficial effect of RA for pregnant women may be associated with the beneficial effect for the development of foetus as well.

The strengths of the study are that HCCSCA is a populationbased large data set including 104 women with prospectively and medically recorded RA during the pregnancy in an ethnically homogeneous Hungarian (Caucasian) population. Additional strengths are the matching of cases to controls without CA and the availability of data of most confounders. The validity of CA diagnosis was good, because cases with CA were reported by medical doctors to HCAR and their diagnoses were modified if necessary on the basis of recent medical examinations in HCCSCA. The diagnosis of birth outcomes was based on medical records.

However, this data set has also limitations. We did not know anything on the other pregnancy outcomes, e.g. miscarriages of women with RA. Our study period was between 1980 and 1996, therefore we were not able to evaluate the recently marketed drugs for the treatment of RA during pregnancy (35-37). Another weakness of our study is the lack of data regarding smoking habit in all case and control mothers. Our validation study showed the low reliability of retrospective self-reported information on smoking habit in the questionnaire of case mothers while these data of control mothers were mostly correct (29).

In conclusion, the higher risk of adverse birth outcomes including CAs, preterm birth and low birth weight was not found in the children of pregnant women with RA. In fact, higher birth weight may indicate that in general RA is associated with a beneficial effect not only for pregnant women but for the foetuses as well.

\section{Conflict of Interest}

None declared

\section{REFERENCES}

1. Scott DL, Wolfe F, Huizinga TW. Rheumatoid arthritis. Lancet. 2010 Sep 25;376(9746):1094-108.

2. Hankins GDV, Suarez VR. Rheumatologic and connective tissue disorders. In: Creasy RK, Resnik R, Iams JD, editors. Maternal - fetal medicine. 5th ed. Philadelphia: W.B. Saunders; 2004. p. 1147-63.

3. Ostensen M. Sex hormones and pregnancy in rheumatoid arthritis and systemic lupus erythematosus. Ann N Y Acad Sci. 1999 Jun 22;876:13143.
4. Zrour SH, Boumiza R, Sakly N, Mannai R, Korbaa W, Younes M, et al. The impact of pregnancy on rheumatoid arthritis outcome: the role of maternofetal HLA class II disparity. Joint Bone Spine. 2010 Jan;77(1):3640.

5. Tchórzewski H, Krasomski G, Biesiada L, Głowacka E, Banasik M, Lewkowicz P. IL-12, IL-6 and IFN-gamma production by lymphocytes of pregnant women with rheumatoid arthritis remission during pregnancy. Mediators Inflamm. 2000;9(6):289-93.

6. Florea A, Job-Deslandre C. Rheumatoid arthritis and pregnancy. Presse Med. 2008 Nov;37(11):1644-51. (In French.)

7. Wilder RL. Hormones, pregnancy, and autoimmune diseases. Ann N Y Acad Sci. 1998 May 1;840:45-50.

8. Bijlsma JW, Huber-Bruning O, Thijssen JH. Effect of oestrogen treatment on clinical and laboratory manifestations of rheumatoid arthritis. Ann Rheum Dis. 1987 Oct;46(10):777-9.

9. Golding A, Haque UJ, Giles JT. Rheumatoid arthritis and reproduction. Rheum Dis Clin North Am. 2007 May;33(2):319-43, vi-vii.

10. de Man YA, Hazes JM, van de Geijn FE, Krommenhoek C, Dolhain RJ. Measuring disease activity and functionality during pregnancy in patients with rheumatoid arthritis. Arthritis Rheum. 2007 Jun 15;57(5):716-22.

11. Sacks G, Sargent I, Redman C. An innate view of human pregnancy. Immunol Today. 1999 Mar;20(3):114-8.

12. Alvarez-Nemegyei J, Cervantes-Díaz MT, Avila-Zapata F, Marín-Ordóñez J. Pregnancy outcomes before and after the onset of rheumatoid arthritis. Rev Med Inst Mex Seguro Soc. 2011 Nov-Dec;49(6):599-604. (In Spanish.)

13. Hazes JM, Dijkmans BA, Vandenbroucke JP, de Vries RR, Cats A. Pregnancy and the risk of developing rheumatoid arthritis. Arthritis Rheum. 1990 Dec;33(12):1770-5.

14. Nelson JL, Hughes KA, Smith AG, Nisperos BB, Branchaud AM, Hansen JA. Remission of rheumatoid arthritis during pregnancy and maternal-fetal class II alloantigen disparity. Am J Reprod Immunol. 1992 Oct-Dec;28(3-4):226-7.

15. Spector TD, Da Silva JA. Pregnancy and rheumatoid arthritis: an overview. Am J Reprod Immunol. 1992 Oct-Dec;28(3-4):222-5.

16. Barrett JH, Brennan P, Fiddler M, Silman A. Breast-feeding and postpartum relapse in women with rheumatoid and inflammatory arthritis. Arthritis Rheum. 2000 May;43(5):1010-5.

17. Ostensen M, Villiger PM. The remission of rheumatoid arthritis during pregnancy. Semin Immunopathol. 2007 Jun;29(2):185-91

18. Clowse ME, Chakravarty E, Costenbader KH, Chambers C, Michaud K. Effects of infertility, pregnancy loss, and patient concerns on family size of women with rheumatoid arthritis and systemic lupus erythematosus. Arthritis Care Res (Hoboken). 2012 May;64(5):668-74.

19. Nelson JL, Hughes KA, Smith AG, Nisperos BB, Branchaud AM, Hansen JA. Maternal-fetal disparity in HLA class II alloantigens and the pregnancy-induced amelioration of rheumatoid arthritis. N Engl J Med. 1993 Aug 12;329(7):466-71.

20. Adams KM, Yan Z, Stevens AM, Nelson JL. The changing maternal "self" hypothesis: a mechanism for maternal tolerance of the fetus. Placenta. 2007 May-Jun;28(5-6):378-82.

21. Yan Z, Lambert NC, Ostensen M, Adams KM, Guthrie KA, Nelson JL. Prospective study of fetal DNA in serum and disease activity during pregnancy in women with inflammatory arthritis. Arthritis Rheum. 2006 Jul;54(7):2069-73.

22. Adams Waldorf KM, Nelson JL. Autoimmune disease during pregnancy and the microchimerism legacy of pregnancy. Immunol Invest. 2008;37(5):631-44.

23. Shepard TH, Lemire RJ. Catalog of teratogenic agents. 11th ed. Baltimore: The Johns Hopkins University Press; 2004.

24. Bowden AP, Barrett JH, Fallow W, Silman AJ. Women with inflammatory polyarthritis have babies of lower birth weight. J Rheumatol. 2001 Feb;28(2):355-9.

25. Czeizel AE, Rockenbauer M, Siffel C, Varga E. Description and mission evaluation of the Hungarian case-control surveillance of congenital abnormalities, 1980-1996. Teratology. 2001 May;63(5):176-85.

26. Czeizel AE. First 25 years of the Hungarian congenital abnormality registry. Teratology. 1997 May;55(5):299-305.

27. Czeizel AE, Intôdy Z, Modell B. What proportion of congenital abnormalities can be prevented? BMJ. 1993 Feb 20;306(6876):499-503.

28. Czeizel AE. Specified critical period of different congenital abnormalities: a new approach for human teratological studies. Congenit Anom (Kyoto). 2008 Sep;48(3):103-9.

29. Czeizel AE, Petik D, Puhó E. Smoking and alcohol drinking during pregnancy. The reliability of retrospective maternal self-reported information. Cent Eur J Public Health. 2004 Dec;12(4):179-83. 
30. Czeizel AE, Petik D, Vargha P. Validation studies of drug exposures in pregnant women. Pharmacoepidemiol Drug Saf. 2003 JulAug;12(5):409-16.

31. Czeizel AE, Vargha P. Periconceptional folic acid/multivitamin supplementation and twin pregnancy. Am J Obstet Gynecol. 2004 Sep;191(3):790-4.

32. Síró B, Czeitzel E. Genetic counselling in partients with rheumatoid arthritis. Az orvostudomány aktuális problémái. 1988;58:79-81. (In Hungarian.)

33. Klareskog L, Catrina AI, Paget S. Rheumatoid arthritis. Lancet. 2009 Feb 21;373(9664):659-72.

34. Bánhidy F, Ács N, Puhó EH, Czeizel AE. Chronic hypertension with related drug treatment of pregnant women and congenital abnormalities in their offspring: a population-based study. Hypertens Res. 2011 Feb;34(2):257-63.
35. Partlett R, Roussou E. The treatment of rheumatoid arthritis during pregnancy. Rheumatol Int. 2011 Apr;31(4):445-9.

36. Makol A, Wright K, Amin S. Rheumatoid arthritis and pregnancy: safety considerations in pharmacological management. Drugs. 2011 Oct 22;71(15):1973-87.

37. 37. Scioscia C, Scioscia M, Anelli MG, Praino E, Bettocchi S, Lapadula G. Intentional etanercept use during pregnancy for maintenance of remission in rheumatoid arthritis. Clin Exp Rheumatol. 2011 Jan-Feb;29(1):93-5.

Received October 18, 2013 Accepted in revised form January 22, 2015 